\title{
Isolation and Identification of Escherichia Species from Faecal Sample of an Elephant and Antibiogram Assay
}

\author{
S. D. Audarya ${ }^{1 *}$, R. Gangil ${ }^{1}$, D. Chhabra ${ }^{1}$, R. Sharda ${ }^{1}$, M. Haque ${ }^{2}$, \\ N. Shrivastava ${ }^{3}$, S. Shukla ${ }^{3}$ and U. K. Garg ${ }^{3}$ \\ ${ }^{1}$ Department of Veterinary Microbiology , ${ }^{2}$ Department of Veterinary Parasitology, \\ ${ }^{3}$ Department of Veterinary Pathology, College of Veterinary Science and Animal Husbandry, \\ Nanaji Deshmukh Veterinary Science University, Harnyakhedi, Dr. Ambedkar Nagar, \\ Mhow-453446, Indore, Madhya Pradesh, India \\ *Corresponding author
}

\section{A B S T R A C T}

\section{Keywords}

Elephant,

Escherichia species,

Antibiogram assay,

Biochemical

characterization,

Carbohydrate

utilization

Article Info

Accepted:

15 October 2020

Available Online:

10 November 2020
In the present study, faecal and blood samples were collected, aseptically, from an elephant arrived to the Veterinary Clinics of the College. Immediately, samples were used for bacterial isolation. A bacterial isolate, isolated from the faecal sample of an elephant was identified at the genus level to be of Escherichia species by adopting Enterobacteriaceae identification kit used for studying biochemical characteristics and carbohydrate utilization tests (Gram negative bacilli showing mainly ONPG positive, oxidase negative and nitrate reduction positive). Mueller Hinton's agar (MHA) was used to conduct antibiogram assay by using the faecal culture. A total of 14 number of antibiotics from 7 different groups were utilized in the investigation namely Chloramphenicol, Ciprofloxacin, Ofloxacin, Levofloxacin, Nitrofurantoin, Norfloxacin, Tetracycline, Streptomycin, Amoxyclov, Amikacin, Ampicillin, Doxycycline hydrochloride, Penicillin G and Erythromycin. Only two antibiotics, Levofloxacin (Quinolone group) and Nitrofurantoin (Nitrofuran antibacterial) were found to be sensitive in the test.

\section{Introduction}

Elephants are one of the heaviest mammals on the earth. It belongs to the family Elephantidae. The family is further divided into two genera; Loxodonta and Elephas. African elephant (Loxodonta africana) and Asian elephant (Elephas maximus) both originated in sub-Saharan Africa. Further, the
African elephant is divided into two subspecies, the savanna elephant Loxodonta africana africana and Loxodonta africana cyclotis (Poole, 1996). Asian elephants are different than their African counterparts in several aspects (smaller size, small ears, only some male Asian elephants have tusks). Elephants help maintain biodiversity of the ecosystems. However, African elephants are 
mainly poached for ivory and Asian elephants face threats due to habitat loss from humananimal conflict (https://www.worldwildlife .org/species/elephant\#: :text=Elephants $\% 20 \mathrm{~h}$ elp $\% 20$ maintain $\% 20$ forest $\% 20$ and,allow $\% 20$ passage\%20for\%20other\%20animals). In 2017, there were around 27,000 elephants (Elephas maximus) in India of which 2500 kept in captivity. The majority (around 1700) of the captive elephants belonged to private individuals). The rest of the captive elephants (800) were with zoos, circuses and temples. Though, a wildlife protection act 1972 is in force, still animals like elephants face inhumane conditions at some places. (https://scroll.in/article/954150/india-is-

pushing-a-plan-to-protect-elephants-in-thewild-but-is-ignoring-animals-incaptivity\#: :text=Despite\%20the\%20odds\%2 C\%20India\%20 has, in \% 202017\% 20 was $\% 20$ around \% 2027\% 2C000). Asian elephants also suffer from infectious diseases including those that cause diarrhoea due to Escherichia coli (Senthilkumar et al., 2020).

In the present study, clinical samples were collected from a she elephant (suffering due to unknown ailments) brought to the Veterinary Clinics for clinical investigation. Isolation and identification of bacteria in pure culture is important for further characterization of the isolate and its antibiogram studies.

Such studies will help in understanding the antibacterial susceptibility profile of the bacterial isolate that can be of help in future for treatment purposes. Hence, the present investigation, reports isolation of a bacteria in pure culture from a faecal sample of an elephant. The study also report, results of antibiogram assay from faecal culture and results of biochemical and carbohydrate utilization tests on the bacterial isolate (the isolate closely resembled to Escherichia species).

\section{Materials and Methods}

\section{Elephant}

A female elephant (close to 35 years old) named Laxmi was brought at Teaching Veterinary Clinical Complex on 12/05/2014 located in the premises of the college by lifting with a Crain from Indore. It was lying in the recumbent condition and the cause of suffering was not known (Fig. 1).

\section{Collection of clinical samples}

Blood sample was collected aseptically from the ear vein in the sterile container. Faecal sample was collected per rectal in the sterile container. Both the samples were collected for bacteriological examination in the morning hours.

\section{Transportation of the samples}

The collected samples were immediately brought to the Department of Veterinary Microbiology laboratory on ice.

\section{Inoculation of the samples in liquid culture media and growth}

In the laboratory broth, the samples were immediately inoculated into the separate tubes with sterile Brain Heart Infusion (BHI) broth, a liquid culture media. After 4-5 hours of inoculation, there was no turbidity in the tube inoculated with blood sample.

Inoculation of the samples on solid culture medias, nutrient agar, MacConkey's agar and Eosin Methylene Blue (EMB) agar

Blood and faecal samples were further inoculated onto nutrient agar and MacConkey's agar (Fig. 2). On overnight incubation at $37^{\circ} \mathrm{C}$, there was no growth in the plate inoculated with the blood sample but 
plates inoculated with faecal sample indicated growth in nutrient agar as well as pink growth due to lactose fermentation on MacConkey's agar. Very next day the bacterial growth on MacConkey's agar was streaked on both EMB agar plates (Fig. 3).

\section{Enterobacteriaceae identification kit}

$\mathrm{Hi} 25^{\mathrm{TM}}$ Enterobacteriaceae identification kit employing standardized colorimetric identification system (biochemical and carbohydrate utilization tests), KB003 (HiMedia, India) was used to identify Enterobacteriaceae species (Fig. 4). The kit employs standardized colorimetric identification system comprised of 25 tests (biochemical and carbohydrate utilization tests) and used in the study. $50 \mu$ l of freshly grown bacterial culture was added in each well of both the strips provided by the manufacturer and incubated at $37{ }^{\circ} \mathrm{C}$ at least for 18 hours before addition of reagents for required tests.

\section{Antibiogram assay}

Antimicrobial susceptibility test or antibiogram assay was conducted using Mueller Hinton's agar, MHA (Bauer et al., 1966). Faecal sample inoculated BHI broth (approx. $3 \mathrm{ml}$ ) showing turbidity after 4 hours was inoculated on MHA plates by pouring. Excess broth was decanted and MHA plates were kept for drying inside the laminar air flow cabinet for 5 minutes. Thereafter, antibiotic sensitivity discs were placed at their respective position on MHA. The plates were incubated overnight at $37{ }^{\circ} \mathrm{C}$. On the next day, after 15 hours of incubation results were recorded. A total of 14 no of antimicrobials were employed in the test based on disc diffusion technique. Antimicrobials/ antibiotics used in the study; namely from groups, Chloramphenicol groupChloramphenicol (30 mcg), Quinolone group-
Ciprofloxacin (5 mcg), Norfloxacin (10 mcg), Ofloxacin $(5 \mathrm{mcg})$, Levofloxacin $(5 \mathrm{mcg})$, Tetracycline group- Tetracycline $(30 \mathrm{mcg})$, Doxycycline hydrochloride (30 mcg), Nitrofuran antibacterial- Nitrofurantoin (300 mcg), Aminoglycoside group-Amikacin (30 $\mathrm{mcg})$, Streptomycin (10 mcg), Penicillins group- Ampicillin (10 mcg), Penicillin G (10 units), Amoxyclov (30 mcg), and MacrolidesErythromycin $(15 \mathrm{mcg})$. The results were interpreted as sensitive or resistant as per the manufacturer's instructions.

\section{Results and Discussion}

In the present study, liquid culture, BHI broth inoculated with faecal sample exhibited turbidity on incubation at $37{ }^{\circ} \mathrm{C}$ for $4-5$ hours duration indicating bacterial growth. On Gram's staining of bacterial smear prepared from broth, coco-bacillary to bacillary organisms were visualized under oil immersion microscopy. Faecal sample inoculated onto nutrient agar and MacConkey's agar and incubated overnight at $37{ }^{\circ} \mathrm{C}$ indicated bacterial growth. Pink coloured colony grown on MacConkey's agar was due to lactose fermentation. The next day, growth on nutrient agar and MacConkey's agar, both, were streaked on EMB agar. Bacterial growth on EMB agar proved to be of Gram negative, rods, however there was no specific metallic sheen observed. On Gram's staining, growth on MacConkey's agar and EMB agar proved to be of gramnegative bacilli.

Hi25 ${ }^{\mathrm{TM}}$ Enterobacteriaceae identification kit, KB003 (HiMedia, India) was employed to identify Enterobacteriaceae spp. as per manufacturer's instructions. The results of biochemical and carbohydrate utilization tests were presented in the figure 2 and compared with the Enterobacteriaceae spp. identification chart given by the manufacturer (HiMedia, India). After following the 
identification chart, it was concluded that the isolate in the study fall close to the genus Escherichia but species level identification was difficult. Gram negative bacteria possessing tests results of ONPG positive, oxidase negative and nitrate reduction positive are placed in the genus Escherichia (Willey et al., 2008). Similar results are observed in the present study. The species level identification for Escherichia species identified was not possible in the study, however, Escherichia coli infection was reported in dung samples of diarrheic captive Asian elephants of Tamil Nadu state in India (Senthilkumar et al., 2020). Escherichia coli bacteria were also isolated from different biological and environmental sources (Zinnah et al., 2007). DNA isolation from faecal samples was reported (Zhang et al., 2006). Faecal genotyping for elephant species was also described, recently (Bourgeois et al., 2019).

Fig.1 She elephant

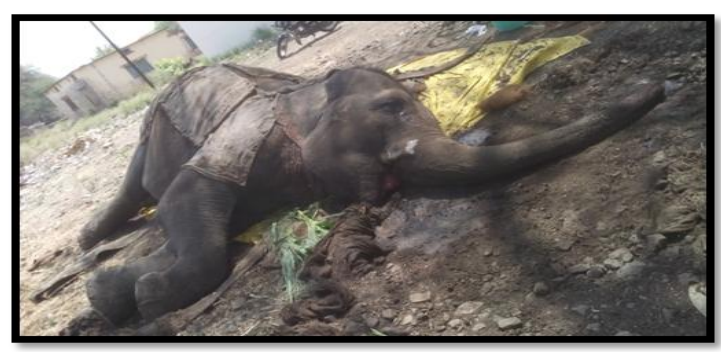

Fig.2 Bacterial culture from faecal and blood samples on agar

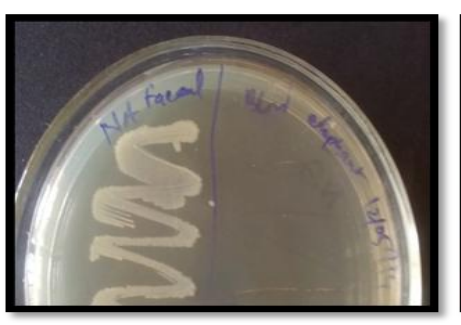

Nutrient agar

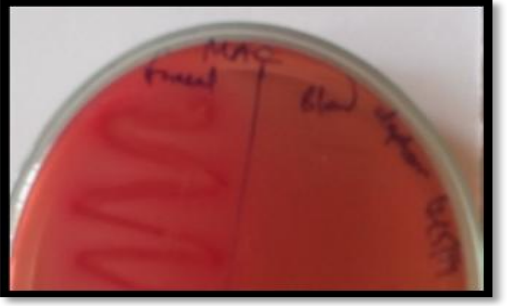

McConkey's agar

Fig.3 Pure culture on EMB agar. (Bacteria reveals no metallic sheen; cultures derived from Nutrient agar (A) and MacConkey's agar (B) respectively streaked on EMB agar, Gram's staining indicated Gram negativity $(\mathrm{C})$

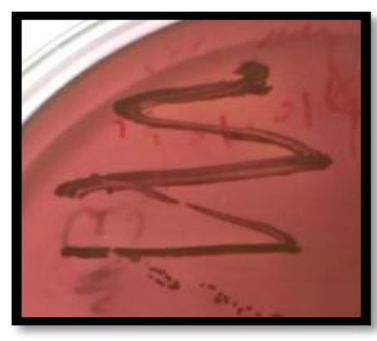

A

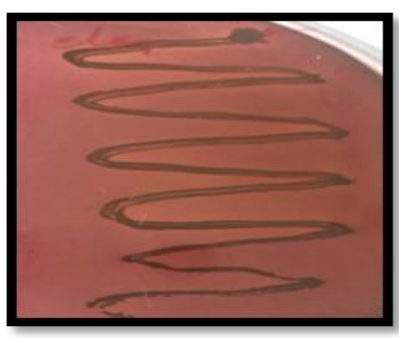

B

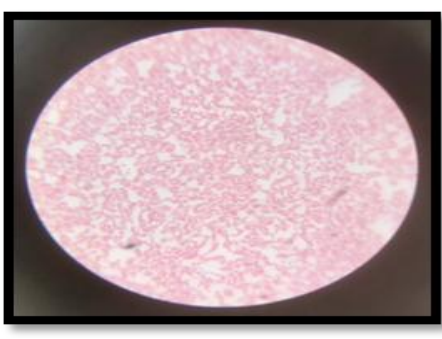

$\mathrm{C}$ 
Fig.4 Results of biochemical and carbohydrate utilization tests for a bacterial isolate from faecal sample of elephant

Plate.1 ONPG (+), Lysine utilisation (+), Ornithine utilisation (+), Urease (-), Phenylalanine deamination (-), Nitrate reduction (+), $\mathrm{H}_{2}$ S production (-), Citrate utilisation (+), VP (-), MR (+), Indole (-), Malonate (-)

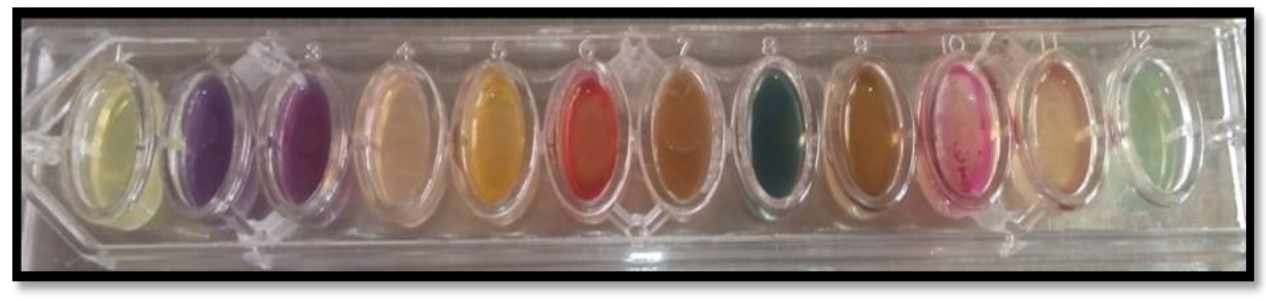

Plate. 2 Esculin hydrolysis (-/+ after 24 hrs), Arabinose (+), Xylose(+), Adonitol (+), Rhamnose (+), Cellobiose (-), Melibiose (+), Saccharose (-/+ after $24 \mathrm{hrs),} \mathrm{Raffinose} \mathrm{(-/+} \mathrm{after} 24 \mathrm{hrs})$, Trehalose (+), Glucose (+), Lactose (+)

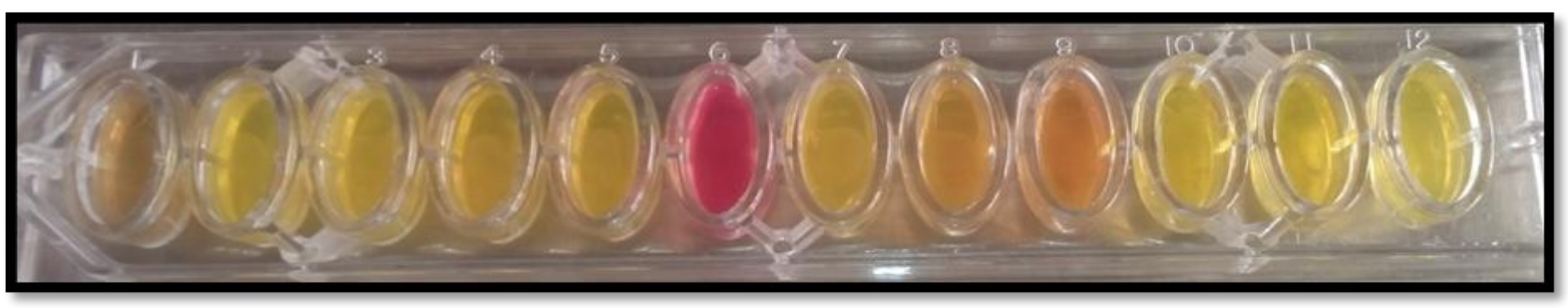

Oxidase test (-): Not shown

In the antibiogram assay, out of 7 different groups of antibiotics, only two groups Nitrofuran antibacterial (Nitrofurantoin) and Quinolone group (Levofloxacin) were found to be sensitive. However, except Levofloxacin other members in the Quinolone group of antibiotics used in the investigation (Ciprofloxacin, Norfloxacin, Ofloxacin) were ineffective. Levofloxacin is the synthetic broad-spectrum antibacterial agent. Levofloxacin is the L-isomer of the racemate Ofloxacin, a Quinolone. It inhibits enzymes required for DNA replication, transcription, repair and recombination (bacterial topoisomerase IV and DNA gyrase, type II topoisomerases). It is effective against aerobic gram-negative microorganisms. Some bacteria resistant to other quinolones may be susceptible to Levofloxacin (https://www. accessdata.fda.gov/drugsatfda_docs/label/2006 /020634s040,020635s043,021721s007lbl.pdf). The present study supports this above statement. Nitrofurantoins reduced by bacterial flavoproteins to reactive intermediates. These reactive intermediates inactivate or alter bacterial ribosomal proteins or other macromolecules (inhibition of processes related to protein synthesis, aerobic energy metabolism, DNA synthesis, RNA synthesis and cell wall synthesis). Nitrofurantoin is shown to be effective against gram positive and negative aerobes (Staphylococcus saprophyticus and Escherichia coli, in-vitro as well as in clinical infections)

(https://www.accessdata.fda.gov/drugsatfda_d ocs/label/2009/020064s019lbl.pdf). Our study also indicated, the in-vitro effectiveness of Nitrofurantoin against isolated Escherichia species. 
Reports from all over the world showed increase in emergence of antibiotic resistant Escherichia coli strains from various clinical sources like uterine infections, mastitic milk, urinary infections, diarrheic cases and sepsis (Iredell et al., 2016), samples from animals (Marshall and Levy, 2011; Onen et al., 2015; Armanullah et al., 2018) and interestingly from environmental samples (Stephanie, 2015). The use of antibiotics in the treatment of diseases and other factors have been linked to the development of resistant microorganisms (Adzitey, 2015). Some of the main anthropogenic source of the antimicrobial resistance bacteria in wildlife already suggested were landfills, insufficiently treated wastewater draining into rivers and lakes and waste from intensively managed livestock farm (Schroeder, et al.,2002; Aarestrup, et al., 2008; Ahlstrom et al., 2019).

Faecal-bacterial transmission between banded mongoose (Mungos mungo) and humans in northern Botswana using Escherichiacoli as a model organism was evaluated (Pesapane et al., 2013). There are very few reports available on the studies of bacterial isolates from elephants. Hence, the present investigation, reports bacterial isolation in pure culture from a faecal sample of an elephant. The study also reports results of antibiogram assay from culture of faecal sample and results of biochemical characteristics and carbohydrate utilization tests on the bacterial isolate from elephant.

\section{Acknowledgements}

The authors are thankful to the supporting staff at the Department of Veterinary Microbiology.

\section{References}

Aarestrup, F.M., Wegener H.C. and
Collignon, P. 2008. Resistance in bacteria of the food chain: Epidemiology and control strategies. Expert Rev. Anti. Infect. Ther. 206:733750.

Adzitey, F. 2015. Antibiotic Resistance of Escherichia coli Isolated from beef and its Related Samples in techiman municipality of Ghana. Asian J. Anim. Sci. 9: 233-240.

Ahlstrom, C.A., Ramey, A.M., Woksepp, H. and Bonnedahl, J. 2019. Repeated detection of carbapenemaseproducing Escherichia coli in gulls inhabiting Alaska. Antimicrob. Agents Chemother., 63:e00758-19. doi:10.1128/AAC.00758-19.

Armanullah, M., Anjay, Kumar, P., Kumari, S., Kaushik, P., Archana and Arya, S.K.D. 2018. Prevalence of multi-drug resistant Escherichia coli in bovine clinical samples. Int. J. Curr. Microbiol. Appl. Sci., Special issue 7: 1476-1485.

Bauer, A.W., Kirby, W.M., Sherris, J.C. and Turck, M. 1966. Antibiotic susceptibility testing by a standardized single disc method. Am. J. Clin. Pathol., 45:493-496.

Bourgeois, S., Kaden, J., Senn, H., Bunnefeld, N., Jeffery, K.J., Akomo-Okoue, E.F., Ogden, R. and McEwing, R. 2019. Improving cost-efficiency of faecal genotyping: New tools for elephant species. PLoS ONE, 14(1): e0210811. https://doi.org/10.1371/journal. pone.0210811

Iredell, J., Brown, J., and Tagg, K. 2016. Antibiotic resistance in Enterobacteriaceae: mechanisms and clinical implications. Br. Med. J., 8: 352:h6420.

Marshall, B.M. and Levy, S.B. 2011. Food animals and antimicrobials: Impact on human health. Clin. Microbiol. Rev., 24(4): 718-733. 
Onen, S.P., Aslantas, O., Yilmaz, E.S., Kurekci, C. 2015. Prevalence of $\beta$ lactamase producing Escherichia coli from retail meat in Turkey. J. Food Sci., 80(9): M2023-M2029.

Pesapane, R., Ponder, M. and Alexander, K.A. (2013). Tracking pathogen transmission at the Human-Wildlife interface: Banded mongoose and Escherichia coli. Eco Hth., https://doi.org/10.1007/s10393-0130838-2.

Poole, J. (1996). The African elephant. In: Studying elephants AWF technical handbook series ed. by Kangwana, K. pp.1-8.

Schroeder, C.M., Zhao, C. DebRoy, C. Torcolini J., Zhao, S., White, D.G., Wagner, D.D., McDermott, P.F., Walker, R.D. and Meng, J. 2002. Antimicrobial resistance of Escherichia coli $\mathrm{O} 157$ isolated from humans, cattle, swine and food. Appl. Environ. Microbiol., 68: 576-581.

Senthilkumar, A., Jayathangaraj, M.G., Valli, A., Thangavelu, A., Gomathinayagam, S. and Sribalaji, N. 2020. Isolation and molecular identification of Escherichia coli in diarhheic captive Asian elephants (Elephas maximus) of Tamil Nadu state, India. Int. J. Curr. Microbiol. Appl. Sci., 9(1): 520-526.

Stephanie, F. 2015. Understanding the contribution of environmental factors in the spread of antimicrobial resistance. Environ. Hlth. Prev. Med., 20: 243-252.

Willey, J. M., Sherwood, L. M. and Woolverton, C. J. 2008. Prescott, Harley and Klein's Microbiology. $8^{\text {th }}$ Ed., McGraw Hill Higher education, USA. pp. 1088.

Zhang, B.W., Li, M., Ma, L.C. and Wei, F.W. 2006. A widely applicable protocol for DNA isolation from faecal samples. Biochem. Genet., 44(11/12):503-512. https://doi.org/10.1007/s10528-0069050-1

Zinnah, M.A., Bari, M.R., Islam, M.T., Hossain, M.T., Rahman, M.T., Haque, M.H., Babu, S.A.M., Ruma, R.P., Islam, M.A. 2007. Characterization of Escherichia coli isolated from samples of different biological and environmental sources. Bangl. J. Vet. Med., 5(1\&2): 25-32.

\section{How to cite this article:}

Audarya, S. D., R. Gangil, D. Chhabra, R. Sharda, M. Haque, N. Shrivastava, S. Shukla and Garg, U. K. 2020. Isolation and Identification of Escherichia Species from Faecal Sample of an Elephant and Antibiogram Assay. Int.J.Curr.Microbiol.App.Sci. 9(11): 2084-2090. doi: https://doi.org/10.20546/ijcmas.2020.911.248 